ARTIGO ORIGINAL

\title{
Compactação do solo causada pelo harvester e intensidade de tráfego do forwarder na colheita florestal
}

\author{
Composition of soil caused by harvester and forwarder traffic intensity in \\ forest harvest
}

Elton da Silva Leite ${ }^{1}$ (D) Jaqueline Silva Santos ${ }^{1}$ (D), Bruno Meira Gomes ${ }^{1}$ (D), Júlio Cézar Azevedo Nóbrega ${ }^{1}$, Rafaela Simão Abrahão Nóbrega' ${ }^{1}$ (])

${ }^{1}$ Universidade Federal do Recôncavo da Bahia - UFRB, Cruz das Almas, BA, Brasil

Como citar: Leite, E. S., Santos, J. S., Gomes, B. M., Nóbrega, J. C. A., \& Nóbrega, R. S. A. (2020). Compactação do solo causada pelo harvester e intensidade de tráfego do forwarder na colheita florestal. Scientia Forestalis, 48(126), e3075. https://doi.org/10.18671/scifor.v48n126.21

\begin{abstract}
Resumo
Objetivou-se com o presente trabalho avaliar o efeito da compactação de um solo causada pelo harvester e intensidade de tráfego do trator autocarregável forwarder na colheita do eucalipto. A resistência à penetração do solo (RSP) foi avaliada antes das operações e após o tráfego das máquinas. A operação do harvester promoveu aumento da RSP 2,4 MPa registrado na camada de 0,3 m de profundidade. 0 aumento do tráfego do forwarder proporcionou maior compactação do solo a partir das primeiras passagens e até a camada de 0,42 m de profundidade, excedendo o limite crítico para o desenvolvimento radicular do eucalipto.
\end{abstract}

Palavras-chave: Colheita de madeira; Resistência à penetração e degradação do solo.

\begin{abstract}
The objective of this work was to evaluate the effect of soil compaction caused by the harvester and traffic intensity of the forwarder tractor in the eucalyptus harvest. The soil penetration resistance (RSP) was evaluated before the operations and after the traffic of the machines. The operation of the harvester promoted an increase of the RSP $2.4 \mathrm{MPa}$ registered in the layer of $0.3 \mathrm{~m}$ of depth. O Increase of the forwarder traffic provided greater compaction of the soil from the first passages and up to the layer of $0.42 \mathrm{~m}$ depth, exceeding the critical limit for the root development of eucalyptus.
\end{abstract}

Keywords: Harvesting of wood; Resistance to penetration and soil degradation.

\section{INTRODUÇÃO}

Os principais sistemas de colheita florestal são: toras curtas (cut-to-length) com uso dos tratores florestais harvester e forwarder e de árvores inteiras (full tree) com uso dos tratores florestais feller buncher, skidder e harvester (processador). Os sistemas de colheita mecanizada de madeira empregado nesse estudo são o de toras curtas, que se tornaram amplamente utilizados em muitos países, como Suécia (98\%), Irlanda (95\%) e Finlândia (91\%), em comparação com o método semimecanizado (Karjalainen et al., 2001; Lopes et al., 2015).

Estas máquinas permitem o aumento da produtividade e redução dos custos operacionais, contudo devido às operações com máquinas cada vez mais pesadas está

Fonte de financiamento: Veracel Celulose S.A., Fundação de Amparo à Pesquisa do Estado da Bahia (FAPESB) e Coordenação de Aperfeiçoamento de

Pessoal de Nível Superior - Brasil (CAPES).

Conflito de interesse: Nada a declarar.

Autor correspondente: jakisilva17@gmail.com

Recebido: 12 setembro 2018.

Aceito: 29 julho 2019

Editor: Francides Gomes da Silva Júnior.

(c) (i) Este é um artigo publicado em acesso aberto (Open Access) sob a licença Creative Commons Attribution, que permite uso, distribuição e reprodução cc. em qualquer meio, sem restrições desde que o trabalho original seja corretamente citado. 
ocasionando impactos negativos nos atributos físicos, químicos e biológicos do solo, a compactação (Rodrigues et al., 2015).

A compactação consiste numa compressão exercida em virtude de uma carga superior a capacidade de suporte do solo, que resulta no aumento da densidade, resistência do solo à penetração (RSP) e diminuição do espaço poroso do solo (Cunha \& Cascão, 2009). A compactação é o aumento na densidade resultante da aplicação e cargas ou pressões externas, dependendo da intensidade da carga aplicada, á compactação pode reduzir a produtividade e aumentar os níveis de erosão (Szymczak et al., 2014).

O incremento da compactação decorrente das operações de colheita florestal mecanizada é mais intenso na camada superficial do solo e em condição de maior umidade, em virtude da sensibilidade dessa camada ao tráfego inadequado das máquinas florestais (Lopes et al., 2015; Sampietro et al., 2015).

Rodrigues et al. (2015) constataram que o tráfego do harvester e forwarder proporcionou maior incremento na RSP nas linhas dos rodados das máquinas nas profundidades de 0,1 a 0,2 m. Para Seixas \& Souza (2007), a maior parte da compactação do solo ocorre já durante as primeiras passagens das máquinas e a forma de minimizar o impacto é a restrição do tráfego das máquinas em áreas menores.

Sampietro \& Lopes (2016), observaram em estudos após o tráfego do feller buncher e do skidder sobre um Cambissolo Húmico Alumínico típico $(\mathrm{CHa})$ de textura franco-argilo-arenosa, que nas passadas iniciais das máquinas houve alteração em todo perfil do solo, causando maiores compactações nas camadas mais profundas, aumentando a RSP, com o aumento da intensidade de tráfego das máquinas. Silva et al. (2011) completa que o número de quatro passadas do forwarder na mesma entrelinha ocasionou maior compactação do solo, causando a degradação na estrutura do solo. Pois o forwarder é uma máquina cogitada para realizar o baldeio das toras já cortadas do interior do talhão para a periferia dos talhões, de modo a evitar a entrada de outros veículos de transporte dentro da floresta (Jesus et al., 2015).

Essas operações ocasionam alteração na estrutura e nos atributos físicos do solo, dificultando o crescimento e a distribuição das raízes no solo. Valores de RSP de 3,0 MPa tem sido aceito como limite crítico para o desenvolvimento do sistema radicular de espécies florestais (Dedecek \& Gava, 2005). Dentre os atributos físicos que são alterados durante as operações de colheita florestal, deve-se ter um controle com o teor de água no solo, pois à medida que a umidade aumenta, diminui a coesão entre as partículas do solo e resistência mecânica torna-se cada vez menor as forças externas, elevando a compactação do solo (Sampietro et al., 2015; Szymczak et al., 2014).

A pesquisa foi desenvolvida em uma região madeireira de muita extensão na Bahia que chama atenção pelos poucos estudos que investigam o comportamento da intensidade de tráfego na compactação de um Latossolo distrocoeso, localizado nos Tabuleiros Costeiros onde estão situadas as principais empresas do setor florestal.

Desta forma, torna-se necessário a realização de estudos que visem contribuir com informações em outras áreas e com outras máquinas de colheita. Para apontar as principais consequências da compactação do solo decorrente da intensidade de tráfego das máquinas usadas na colheita de eucalipto visando estratégias para reduzir a resistência do solo à penetração no setor florestal. Diante do exposto, objetivou-se com o presente trabalho avaliar o efeito da compactação de um solo causada pelo harvester e intensidade de tráfego do trator autocarregável forwarder na colheita do eucalipto.

\section{MATERIAL E MÉTODOS}

O estudo foi realizado no sul da Bahia, em uma área de relevo plano com povoamentos de eucalipto, localizado no Município de Eunápolis - Bahia - Brasil, com volume médio por árvore de 0,39 $\mathrm{m}^{3}$, nesta região o solo é classificado como um LATOSSOLO AMARELO distrocoeso (Santos et al., 2013).

O clima predominante na região é do tipo Af clima tropical úmido, com verão chuvoso e inverno seco, segundo a classificação de Köppen (1948), precipitação anual de 1.200 mm, com 
temperatura média anual de $24,5^{\circ} \mathrm{C}$ (Leão \& Melo, 1990). A altitude média da região é de $180 \mathrm{~m}$ (Novaes \& São José, 1992)

O sistema de colheita foi o de toras curtas (cut to length), sendo a derrubada e processamento das árvores realizado por harvester, enquanto a extração das toras do interior do talhão para a margem da estrada foi realizada pelo forwarder.

O harvester foi constituído por uma máquina base escavador de esteiras da marca komatsu, modelo PC200F, com 18.526 horas, cabeçote da marca Komatsu 370, peso de $23.290 \mathrm{~kg}$, área de contato com o solo de 3,93 $\mathrm{m}^{2}$ (duas esteiras, cada com largura de 0,6 m e comprimento da superfície da esteira em contato com o solo de 3,275 m), pressão sobre o solo de $0,597 \mathrm{kgf} \mathrm{cm}^{2}(0,059 \mathrm{MPa})$

O forwarder utilizado foi o da marca Komatsu modelo 890.3, tração 8x8, Nokian Forest King TRS L-2 750/55×26,5 de baixa pressão e alta flutuação (BPAF), dimensões de $750 \mathrm{~mm}$ de largura, altura do flanco de 412,5 mm (altura de 55\% da largura) e diâmetro interno do pneu de 26,5 polegadas, largura de 2,17 m, pressão interna de 35 PSI, grua 165F com braço telescópico de 9,5 m de alcance, garra G36 com capacidade de 0,36 m², apresentando 10.319 horas de trabalho, peso sem carga de $19.100 \mathrm{~kg}$, e capacidade de volume de madeira de $16.2 \mathrm{~m}^{3}$, determinado pelo xilômetro, "Pivotex", e a carga foi de $17.932 \mathrm{~kg}$, totalizando peso total com carga de $37.032 \mathrm{~kg}$. A distância de baldeio foi em média de $191 \mathrm{~m}$ e máxima de

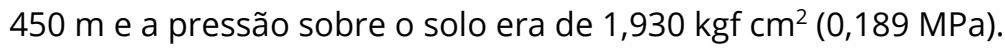

As análises físicas do solo foram realizadas no laboratório de solos da Universidade Federal do Recôncavo da Bahia - UFRB, localizado no campus de Cruz das Almas - BA, Brasil. Foram realizadas coletas de amostras indeformadas por meio do método do anel volumétrico de Uhland em três níveis de profundidade do perfil do solo: 0,0-0,2; 0,2-0,4 e 0,4-0,6 m, cada uma com seis repetições e em cinco pontos de tráfego de máquinas. Os parâmetros físicos avaliados foram: analise granulométrica, umidade, densidade do solo e resistência à penetração (Tabela 1).

Tabela 1. Caracterização granulométrica de um Latossolo Amarelo distrocoeso localizado na região de Eunápolis, Bahia, Brasil.

\begin{tabular}{|c|c|c|c|c|c|c|c|}
\hline \multirow{3}{*}{ Prof. (m) } & \multicolumn{5}{|c|}{ Areia } & \multirow{3}{*}{ DS $\mathrm{g} \mathrm{cm}^{-3}$} & \multirow{3}{*}{ UG } \\
\hline & Total & Grossa & Fina & Silte & Argila & & \\
\hline & \multicolumn{5}{|c|}{ 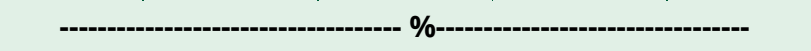 } & & \\
\hline $0,0-0,2$ & 32 & 13 & 7 & 28 & 40 & 1,56 & $9,33 \%$ \\
\hline $0,2-0,4$ & 43 & 17 & 7 & 19 & 38 & 1,68 & $10,10 \%$ \\
\hline $0,4-0,6$ & 38 & 13 & 8 & 22 & 40 & 1,7 & $10,10 \%$ \\
\hline
\end{tabular}

DS- densidade do solo, UG - umidade gravimétrica.

A umidade do solo foi determinada através do método gravimétrico, obtido pela relação entre a massa de água e a massa de solo da amostra seca, a partir da massa de solo seca foi estimada a densidade, por meio de estufa a $105{ }^{\circ} \mathrm{C}$ por 24 horas, como descritos por Donagema et al. (2011).

A resistência do solo à penetração foi determinada por meio de penetrômetro digital automático da marca Falker modelo SoloStar, equipado com uma ponta em forma de cone e ângulo de vértice de 30 graus, acoplado no trator agrícola, equipamento em conformidade com a norma ASAE S313.3 (American Society of Agricultural and Biological Engineers, 2013). Foram registrados os valores a cada $0,01 \mathrm{~m}$ de profundidade, conforme descrito por Lima et al. (2008) e Mercante et al. (2003).

As leituras de RSP foram realizadas in situ nas linhas de tráfego dos rodados, direito e esquerdo das máquinas e em cinco pontos de coleta, com cinco repetições. O modelo operacional consistiu pelo tráfego de uma passada do harvester e pela quantidade de passadas do forwarder, até cinco vezes no mesmo ponto, conforme descrito na Figura 1. 


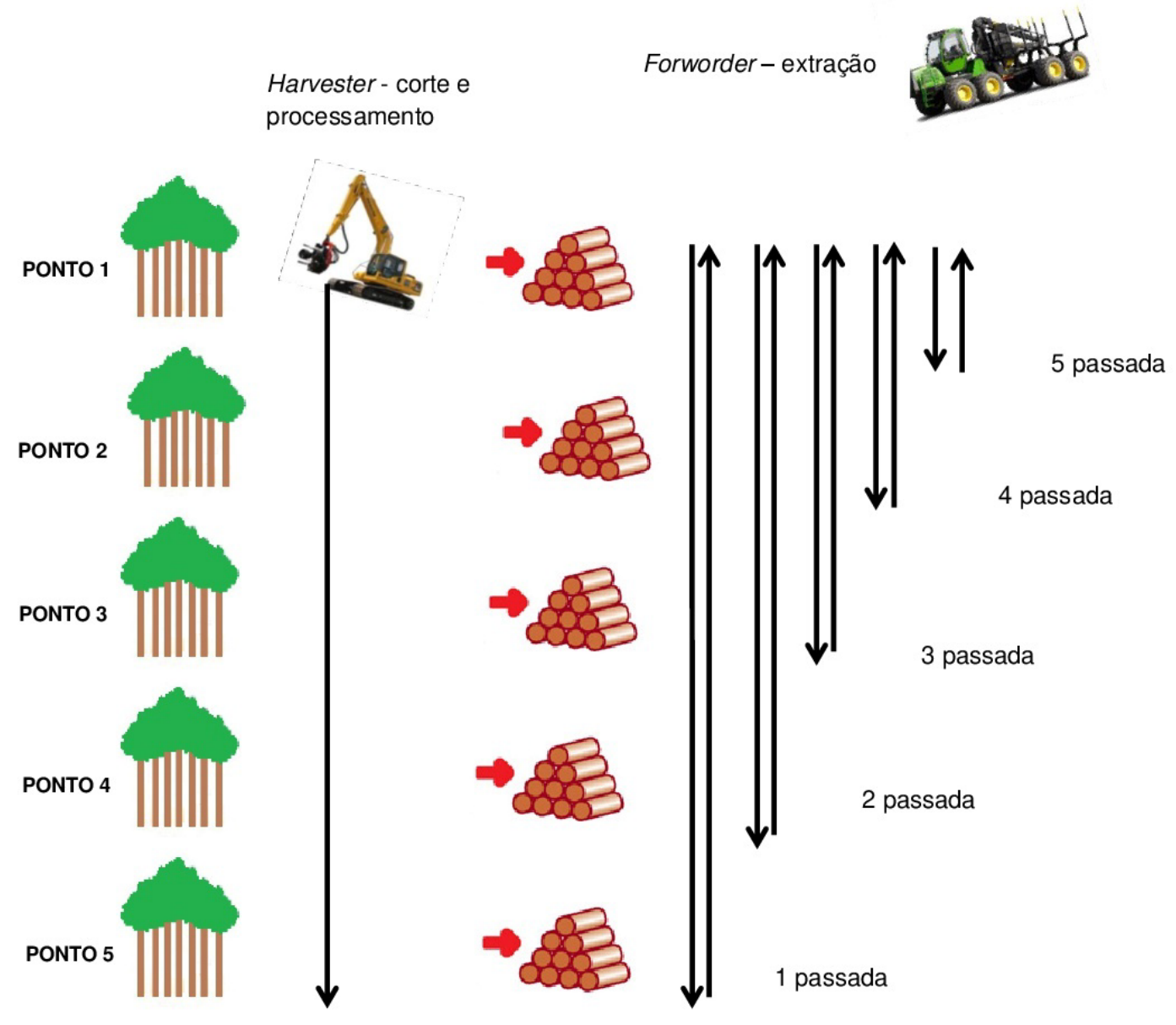

\footnotetext{
Legenda:

$\downarrow$ Sentido de deslocamento do Harvester

$\downarrow$ Sentido de deslocamento do Forworder descarregado

个 Sentido de deslocamento do Forworder carregado
}

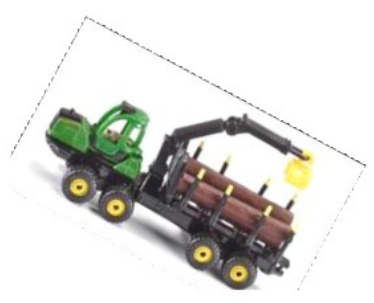

Figura 1. Modelo operacional do harvester e forwarder na colheita do eucalipto.

As análises consistiram pela estatística descritiva para estudar a tendência e dispersão dos dados, bem como a forma de distribuição e média da RSP nas seguintes condições: 1- antes da colheita (AC), 2- após o harvester (HV), 3- após a 1 passada do harvester e 1 passada do forwarder (HV + 1FW), 4- após 1 passada do harvester e 2 passada do forwarder (HV + 2FW), 5- após 1 passada do harvester e 3 passada do forwarder (HV + 3FW), 6- após 1 passada do harvester e 4 passada do forwarder (HV + 4FW), 7- após 1 passada do harvester e 5 passada do forwarder (HV + 5FW). Avaliando a compactação do solo pelo trator autocarregável forwarder em função do número de passadas.

A normalidade dos dados foi verificada pelo teste de Kolmogorov-Smirnov a 5\% de significância. Com esse conjunto de dados, confeccionou-se a associação entre a profundidade e a RSP no plano $(x, y)$ e procedeu-se com um conjunto de curvas das operações do módulo de colheita. 


\section{RESULTADOS E DISCUSSÃO}

A Tabela 1 apresenta os valores de umidade do solo e a partir da análise granulométrica das amostras de solo, verifica-se que a classe textural nas profundidades de $0,0-0,2 ; 0,2-0,4$; 0,4-0,6 $\mathrm{m}$ foi franco-argilo-arenosa. A menor densidade do solo ocorreu na profundidade de 0 a $0,2 \mathrm{~m}$ de $156 \mathrm{gcm}^{-3} \mathrm{e}$ o incremento máximo de densidade do solo neste estudo foi de $1,70 \mathrm{gcm}^{-3}$ registrado na maior profundidade $(0,4-0,6 \mathrm{~m})$.

Nas profundidades entre 0,15 a 0,20 m do solo evidencia-se aumento da resistência do solo a penetração em ambas as condições de trafego, com aumento gradual nas camadas mais profundas à medida que ocorre a redução dos resíduos orgânicos e aumento do número de passagens das maquinas no perfil do solo.

Este aumento da resistência do solo a penetração nas camadas mais profundas refletiuse na densidade do solo, característica dos solos coesos desta região. Os talhões analisados possuem classe textural franco-argilo-arenosa, sendo um fator determinante na sua densidade, conforme exposto por Reinert et al. (2008).

Observou-se que após o tráfego do harvester que o maior incremento da compactação do solo ocorreu na camada de 0,35-0,42 m com valores de RSP que varia de 2,4 a 4,0 MPa antes da primeira passada do forwarder (Figura 2).

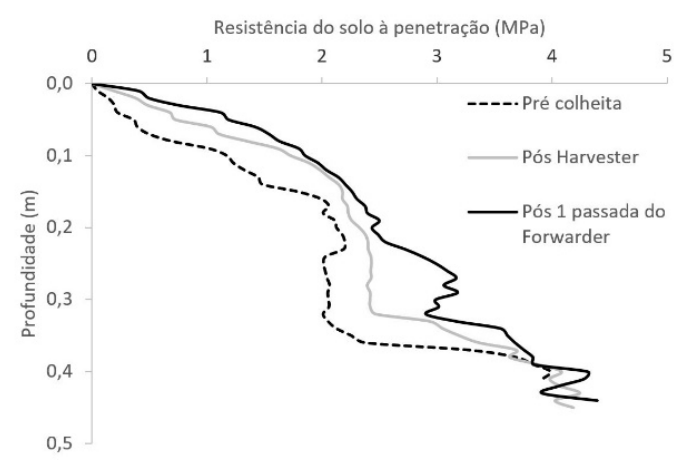

Figura 2. Resistência do solo à penetração (RSP) pré colheita, pós o tráfego do harvester e pós 1 passada do forwarder.

Esses incrementos de RSP ocasionados após o tráfego das máquinas nas camadas mais profundas do solo $(0,3-0,42 \mathrm{~m})$, sobretudo, após a efetivação da primeira passada do forwarder carregado, são similar aos resultados encontrados por Seixas \& Souza (2007), que relataram que a maior parte da compactação do solo ocorre já durante as primeiras passadas e intensidade de tráfego e carga de madeira dos forwarders, entretanto os maiores valores de resistência do solo à penetração foram encontrados nas camadas superficiais $(0$ a $0,2 \mathrm{~m})$. Rodrigues et al. (2015), também observaram que o tráfego do harvester e forwarder proporcionou maior incrementos na resistência à penetração com maior variabilidade nos $0,2 \mathrm{~m}$ superficiais do solo.

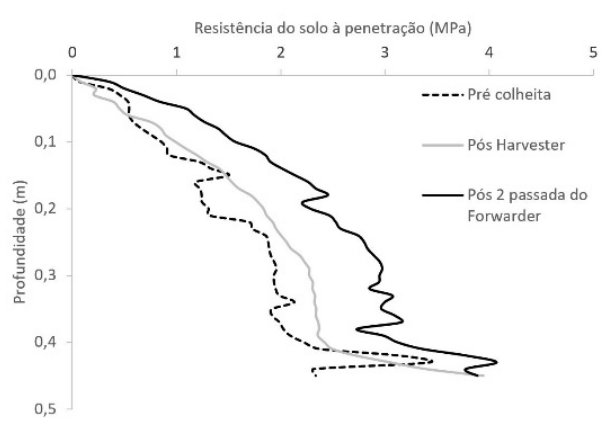

Figura 3. Resistência do solo à penetração (RSP) pré e pós o tráfego do harvester e 2 passadas do forwarder. 


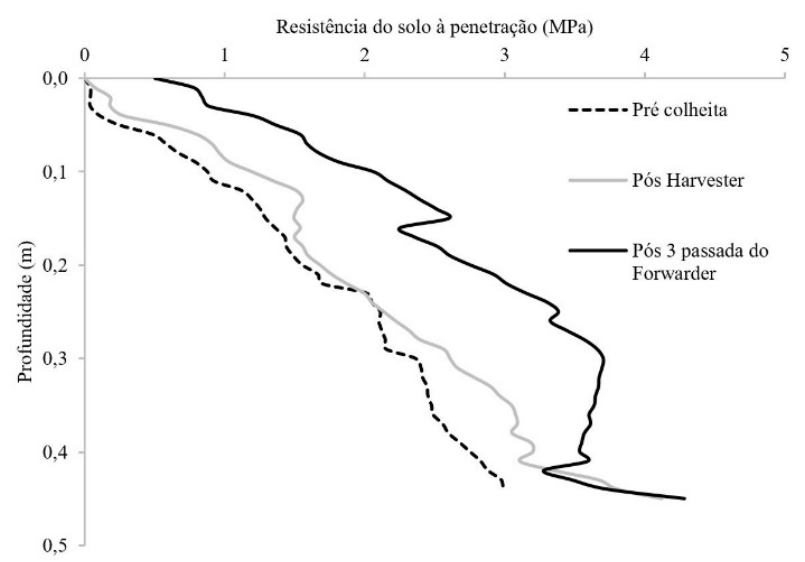

Figura 4. Resistência do solo à penetração (RSP) pré e pós o tráfego do harvester e 3 passadas do forwarder.

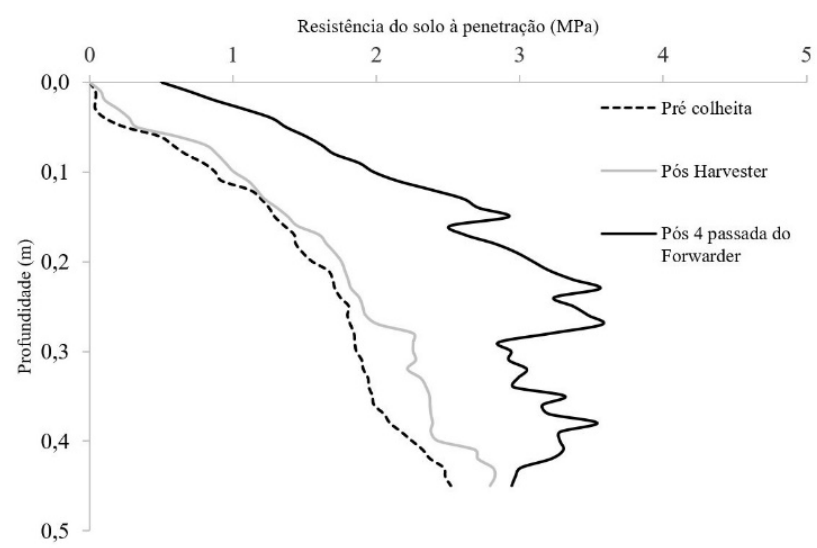

Figura 5. Resistência do solo à penetração (RSP) pré e pós o tráfego do harvester e 4 passadas do forwarder.

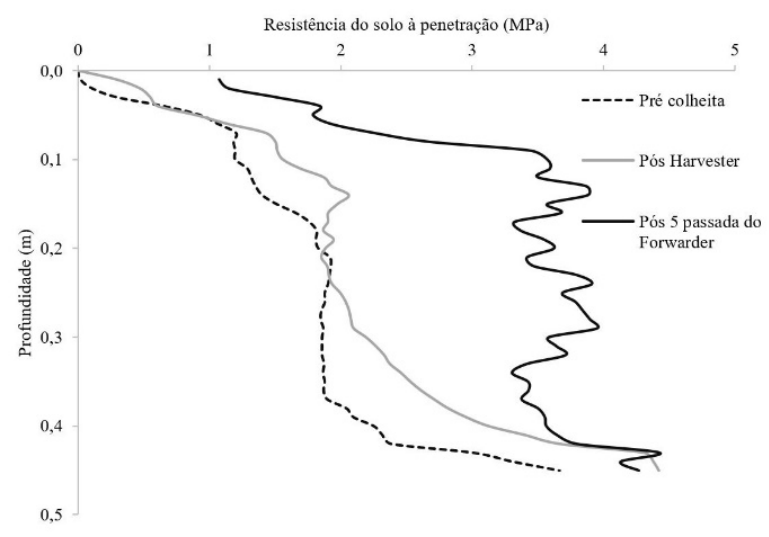

Figura 6. Resistência do solo à penetração (RSP) pré e pós o tráfego do harvester e 5 passadas do forwarder.

Após cinco passadas do forwarder observou-se que ocorreu aumento gradual da compactação do solo e evidenciou em maiores profundidades do solo, a 0,1 $\mathrm{m}$ do solo apresentou valores de resistência de 1,8 MPa de incremento. Evidenciou-se comportamento semelhante entre os tratamentos (HV + 2FW) (Figura 3), (HV + 3FW) (Figura 4) e (HV + 4FW) (Figura 5). A resistência do solo a penetração é ampliado no horizonte 0,2 a 0,4 m, ocorre em virtude do aumento do teor de umidade e das pressões aplicadas pelo tráfego das máquinas acima da capacidade de suporte de carga do solo neste horizonte. 
A frequência do tráfego do forwarder após a primeira passada é um fator preocupante ao desenvolvimento do sistema radicular do eucalipto, com valores de RSP de $3 \mathrm{MPa}$ aos 0,3 m de profundidade. Essa condição atingiu o seu ponto mais crítico após 5 passadas do forwarder, com valores de resistência de 3,5 MPa nos 0,2 m superficiais do solo (Figura 6).

Este fato evidenciou que no perfil do solo verificou que tanto o tráfego do harvester quanto o número de passadas do forwarder apresentou aumento significativo da compactação do solo. Além disto, confirmou que a RSP aumenta gradativamente em profundidade com o número de passagens do forwarder, ocorrendo aumento médio de 0,5 MPa por número de passada. O forwarder resultou em maior incremento da resistência do solo à penetração em virtude do maior número de passada e maior pressão sobre o solo.

Os menores valores de (1,5 a 2,6 MPa) de RSP encontrados nos 0,0 - 0,1 m superficiais do solo após o tráfego das máquinas estão associados ao acúmulo resíduos orgânicos que permanece no solo durante o corte e processamento realizado pelo harvester e durante o baldeio realizado pelo forwarder que favorecem a dissipação da pressão exercida sob o solo, fato relatado por Szymczak et al. (2014).

Estudos realizado por Lopes et al. (2015), avaliando a compactação do solo após o tráfego do harvester e do forwarder na colheita de madeira em plantio de Pinus, constataram que o tráfego das máquinas no sistema de toras curtas acarretou um baixo nível de compactação, com maiores impactos ocorridos na camada superficial com valores de RSP inferiores a $2 \mathrm{MPa}$, não excedendo o limite critico.

Szymczak et al. (2014), avaliando a compactação do solo ocasionada pelo tráfego do harvester e forwarder em plantio de Pinus obtiverem resultados diferentes ao deste estudo, as operações de colheita impactaram o solo na camada superficial 0,1 m, causando compactação nas linhas de tráfego das máquinas.

Estes resultados diferem deste estudo, pois as máquinas aqui avaliadas proporcionaram maior compactação nas camadas subsuperficial do solo. Os fatos podem ocorrer em virtude do gradiente textural do solo, teor de umidade, declividade do terreno, frequência do tráfego e carga e pressão sobre o solo aplicada durante a colheita do eucalipto. Pois conforme relatado por Silva \& Carvalho (2007), Lopes et al. (2011), é comum a ocorrência de Latossolo amarelo nos Tabuleiro Costeiro, que apresentam manifestação do caráter coeso atingindo maior profundidade, resistência ao cisalhamento do solo e impedindo o crescimento das raízes.

Tal resultado obtido está de acordo com o estudo realizado por Lopes et al. (2011), que ao determinar o efeito da umidade na compactação do solo na colheita de madeira por um feller buncher e um skidder em plantio de pinus, verificou-se que os maiores incrementos da compactação do solo após o tráfego dos tratores, ocorreram em condição de maior umidade, com alterações na RSP acima de 2 e $3 \mathrm{MPa}$ atingindo até $0,8 \mathrm{~m}$ de profundidade.

Resultados que corroboram com os encontrados também foram demostrados por Pincelli \& Nunes (2014), Sampietro \& Lopes (2016), em que analisando a RSP em profundidade no sistema de arvores inteiras após o tráfego do feller buncher e skidder, constataram que os maiores valores de resistência do solo à penetração ocorreram nas passadas inicias das máquinas, aumentando gradualmente conforme o número de passadas ao longo do perfil com aumento da profundidade atingindo valores máximos na camada de 0,3 a 0,4 m.

Após o tráfego de cinco passadas do forwarder, corroborou com incrementos de RSP acima de 4,0 MPa nas camadas mais profundas, sendo perceptível que as camadas subsuperficial do solo sofreu maiores impactos com o tráfego das máquinas. Resultados similares foram encontrados por Silva et al. (2007), que observaram em seu estudo que o maior efeito da compactação do solo ocorreu após a realização de quatros passadas do forwarder, com aumento da RSP especialmente na camada de 0,05-0,25 m de profundidade. Lopes et al. (2015), completa que as operações de baldeio com forwarder contribui com aumento da compactação do solo, ocasionado pelas sucessivas passadas nas linhas de extração, sendo importante ressaltar a importância da restrição do número de passadas na área com intuito de reduzir os impactos ocasionados no perfil do solo. 
O trânsito intenso das máquinas nos talhões durante a colheita de eucalipto ao promoverem valores de resistência acima 2,0 $\mathrm{MPa}$, pode ser restritivo ao crescimento das plantas, com riscos de deformações na morfologia das raízes, necessitando do rompimento das camadas compactadas por meio da escarificarão ou subsolagem, fato este constatado por Reinert et al. (2008), Reichert et al. (2007), Cunha \& Cascão (2009), Dedecek \& Gava (2005).

O aumento dos valores de RSP com o aumento da profundidade também foi observado por Oliveira Filho et al. (2016) que ao determinar a resistência do solo à penetração em áreas sob cultivo de cana-de-açúcar, observaram que a camada de 0,3 e 4,0 m (7,33 MPa) foi a camada mais compactada, necessitando da descompactação através da subsolagem. Lima et at. (2013) ao avaliar a compactação em diferentes classes texturais sob cultivo de cana-deaçúcar, obtiverem os maiores valores de resistência do solo à penetração em solos francoargilo-arenosa de 4,7 MPa, na camada de 0,2-0,3 m.

Cavalieri et al. (2009), analisando a compactação em solos sob solos de textura francoargilo-arenosa, verificaram que os maiores valores de resistência à penetração nas camadas ocorreram a partir de 0,1 m de profundidade. Lima et al. (2013) completa que a classe textural franco- argilo-arenosa é a que tem maior distribuição das frações granulométricas, que, pelo rearranjo das partículas de diferentes tamanhos, contribuindo para que a resistência à penetração atingisse os níveis mais elevados na camada (0,0 - 3,0 m).

Nagahama et al. (2016) verificaram que o aumento da resistência do solo à penetração com o aumento da profundidade em solos argilosos, ocorreram devido a acumulação natural das argilas e a redução dos resíduos orgânicos no perfil do solo. Já Carvalho et al. (2008) atribuíram esse aumento da resistência do solo à penetração em profundidade em consequência do sistema de colheita mecanizado que exercem uma grande pressão no solo, fato que corrobora com a compactação do solo, sobretudo nas camadas subsuperficiais $(0,2-3,0 \mathrm{~m})$.

Desta forma, percebe-se que o solo estudado se encontrava compactado até as camadas mais profundas e apresentou maior resistência do solo à penetração, sendo essa uma tendência natural para solos com caráter coesivo, quando somado às pressões exercidas pelo tráfego do harvester e sucessivas passadas do forwarder, contribuíram com os impactos nas camadas subsuperficial do solo.

\section{CONCLUSÕES}

O tráfego do trator autocarregável forwarder proporcionou aumento da densidade e resistência do solo à penetração já durante as primeiras passadas e com a intensidade do tráfego aumentou gradualmente a compactação do solo após a efetivação de cinco passadas, com maiores impactos nas camadas mais profundas 0,3 a 0,42 $\mathrm{m}$.

A operação do harvester promoveu aumento da resistência do solo à penetração até a camada de 0,35- 0,42 m de profundidade.

A operação de extração de madeira com forwarder contribuiu para o incremento da compactação do solo, ocasionado pelas inúmeras passadas na linha de tráfego, limitando o desenvolvimento radicular para a cultura do eucalipto.

\section{REFERÊNCIAS}

American Society of Agricultural and Biological Engineers - ASABE. (2013). ASABE standard S313.3: soil cone penetrometer. St Joseph: ASABE. Recuperado em 19 de abril de 2017, de https://elibrary.asabe.org/standards.asp

Carvalho, L. A., Neto, V. J. M., Silva, C. F., Pereira, J. G., Nunes, W. A. G. A., \& Chaves, C. H. C. (2008). Resistência mecânica do solo à penetração (RMP) sob cultivo de cana-de-açúcar, no município de Rio Brilhante - MS. Agrarian (Dourados), 1, 7-22.

Cavalieri, K. M. V., Silva, Á. P., Arvidsson, J., \& Tormena, C. A. (2009). Influência da carga mecânica de máquina sobre propriedades físicas de um Cambissolo Háplico. Revista Brasileira de Ciência do Solo, 33(3), 477-485. http://dx.doi.org/10.1590/S0100-06832009000300001. 
Cunha, J. P. A. R., \& Cascão, V. N. (2009). REIS, E.F. Compactação causada pelo tráfego de trator em diferentes manejos de solo. Revista Acta Scientiarum Agronomy, 31(3), 371-375.

Dedecek, R. A., \& Gava, J. L. (2005). Influência da compactação do solo na profundidade da rebrota de eucalipto. Revista Árvore, 29(3), 383-390. http://dx.doi.org/10.1590/S0100-67622005000300005.

Donagema, G. K., Campos, D. V. B., Calderano, S. B., Teixeira, W. G., \& Viana, J. H. M. (Org.). (2011). Manual de métodos de análise de solos (2. ed.). Rio de Janeiro: Embrapa Solos.

Jesus, G. L., Silva, I. R., Almeida, L. F. J., Santos, M. A., Leite, F. P., \& Neves, J. C. L. (2015). Produtividade do eucalipto, atributos físicos do solo e frações da matéria orgânica influenciadas pela intensidade de tráfego e resíduos de colheita. Revista Brasileira de Ciência do Solo, 39(4), 1190-1203. http://dx.doi.org/10.1590/01000683rbcs20140494.

Karjalainen, T., Zimmer, B., Berg, S., Welling, J., Schwaiger, H., Finér, L., \& Cortijo, P. (2001). Energy, carbon and other material flows in the Life Cycle Assessment of forestry and forest products. Achievements of the Working Group 1 of the COST Action E9 (68 p.). Finlândia: European Forest Institute.

Köppen, W. (1948). Climatologia com um estudio de los climas de la tierra (478 p.). México: Fondo de Cultura Econômica.

Leão, A. C., \& Melo, A. O. (1990). Características morfológicas, físico-químicas e mineralógicas dos solos da estação ecológica de Pau-Brasil. Agrotropica, 2(2), 105-112.

Lima, J. S. S., Oliveira, P. C., Oliveira, R. B., \& Xavier, A. C. (2008). Métodos geoestatísticos no estudo da resistência do solo à penetração em trilha de tráfego de tratores na colheita de madeira. Revista Árvore, 32(5), 931-938. http://dx.doi.org/10.1590/S0100-67622008000500018.

Lima, R. P., León, M. J. D., \& Silva, A. R. (2013). Compactação do solo de diferentes classes texturais em áreas de produção de cana-de açúcar. Revista Ceres, 60(1), 16-20. http://dx.doi.org/10.1590/S0034737X2013000100003.

Lopes, E. S., Oliveira, D., Rodrigues, C. K., \& Drinko, C. H. (2015). Compactação de um solo submetido ao tráfego do Harvester e do Forwarder na colheita de madeira. Floresta e Ambiente, 22(2), 223-230. http://dx.doi.org/10.1590/2179-8087.046413.

Lopes, E. S., Sampietro, J. A., Lombardi, K. C., \& Dias, A. N. (2011). Avaliação da umidade na compactação do solo submetido ao tráfego de máquinas de colheita florestal. Revista Árvore, 35(3), 659-667.

Mercante, E., Uribe-Opazo, M. A., \& Souza, E. G. (2003). Variabilidade espacial e temporal da resistência mecânica do solo à penetração em áreas com e sem manejo químico localizado. Revista Brasileira de Ciência do Solo, 27(6), 1149-1159. http://dx.doi.org/10.1590/S0100-06832003000600019.

Nagahama, H. J., Cortez, J. W., Pimenta, W. A., Patrocinio Filho, A. P., \& Souza, E. B. (2016). Resistência do solo à penetração em sistemas de preparo e velocidades de deslocamento do trator. Comunicata Scientiae, 7(1), 56-65. http://dx.doi.org/10.14295/cs.v7i1.439.

Novaes, A. B., \& São José, A. R. (1992). Caracterização da região da mata de cipó no sudeste da Bahia. A. B. Novaes, A. R. São José, A. A. Barbosa \& I. Vilas Boas, Reflorestamento no Brasil (pp. 7-16). Vitória da Conquista: UESB.

Oliveira Filho, F. X., Miranda, N. O., Medeiros, J. F., Silva, P. C. M., Mesquita, F. O., \& Costa, T. K. G. (2016). Compactação de solo cultivado com cana-de-açúcar em Baía Formosa, Rio Grande do Norte. Revista Ceres, 63(5), 715-723. http://dx.doi.org/10.1590/0034-737x201663050017.

Pincelli, A. L. P. S. M., \& Nunes, F. S. R. (2014). Compactação e fertilidade do solo após colheita do eucalipto utilizando feller buncher e skidder. Revista Ceres, 20(2), 191-198.

Reichert, J. M., Suzuki, L. E. A. S., \& Reinert, D. J. (2007). Compactação do solo em sistemas agropecuários e florestais: identificação, efeitos, limites críticos e mitigação. In C. A. Cerreta, L. S. Silva \& J. M. Reichert (Eds.), Tópicos em ciência do solo (Vol. 5. pp. 49-134). Viçosa: Sociedade Brasileira de Ciência do Solo.

Reinert, D. J., Albuquerque, J. A., Reichert, J. M., Aita, C., \& Andrada, M. M. C. (2008). Limites críticos de densidade do solo para o crescimento de raízes de plantas de cobertura em argissolo vermelho. Revista Brasileira de Ciência do Solo, 32(5), 1805-1816. http://dx.doi.org/10.1590/S010006832008000500002

Rodrigues, C. K., Lopes, E. S., Müller, M. M. L., \& Genú, A. M. (2015). Variabilidade espacial da compactação de um solo submetido ao tráfego de harvester e forwarder. Revista Scientia Forestalis, 43(106), 387-394..

Sampietro, J. A., \& Lopes, E. S. (2016). Compactação de um cambissolo causada por máquinas de colheita florestal especializada com geoestatística. Revista Floresta, 46(3), 307-314. http://dx.doi.org/10.5380/rf.v46i3.37217. 
Sampietro, J. A., Lopes, E. S., \& Reichert, J. M. (2015). Compactação causada pelo tráfego de feller buncher e skidder em um neossolo regolítico sob distintas umidades. Revista Ciência Florestal, 25(1), 239-248.

Santos, H. G., Jacomine, P. K. T., Anjos, L. H. C., Oliveira, V. A., Lumbreras, J. F., Coelho, M. R., Almeida, J. A., Cunha, T. J. F., \& Oliveira, J. B. (2013). Sistema brasileiro de classificação de solos (3. ed., 353 p). Brasília: Embrapa.

Seixas, F., \& Souza, C. R. (2007). Avaliação e feito da compactação do solo, devido à frequência de tráfego, na produção de madeira de eucalipto. Revista Árvore, 31(6), 1047-1052. http://dx.doi.org/10.1590/S0100-67622007000600009.

Silva, A. J. N., \& Carvalho, F. G. (2007). Coesão e resistência ao cisalhamento relacionadas a atributos físicos e químicos de um Latossolo Amarelo de tabuleiro costeiro. Revista Brasileira de Ciência do Solo, 31(5), 853-862. http://dx.doi.org/10.1590/S0100-06832007000500003.

Silva, A. R., Dias Júnior, M. S., \& Leite, F. P. (2011). Avaliação da intensidade de tráfego e carga de um forwarder sobre a compactação de um Latossolo Vermelho-amarelo. Revista Árvore, 35(3), 547-554. http://dx.doi.org/10.1590/S0100-67622011000300017.

Silva, S. R., Barros, N. F., Costa, L. M., Mendonça, E. S., \& Leite, F. P. (2007). Alterações do solo influenciadas pelo tráfego e carga de um "forwarder" nas entrelinhas de uma floresta de eucalipto. Revista Brasileira de Ciência do Solo, 31(2), 371-377. http://dx.doi.org/10.1590/S010006832007000200019.

Szymczak, D. A., Brun, E. J., Reinert, D. J., Frigotto, T., Mazzalira, C. C., Dal'Col Lúcio, A., \& Marafiga, J. (2014). Compactação do solo causada por tratores florestais na colheita de Pinus taeda L. na região sudoeste do Paraná. Revista Árvore, 38(4), 641-648. http://dx.doi.org/10.1590/S010067622014000400007.

Contribuição dos Autores: ESL: Administração do projeto, conceitualização, captação de recursos, supervisão, redação, revisão e curadoria dos dados; JSS: conceituação, análise formal, software, metodologia, redação e revisão; BMG: coleta de dados, metodologia, analise formal e primeira redação; JCAN: Escrita - Revisão e Edição; RSAN: Escrita - Revisão e Edição. 